\title{
Influencia de la actividad física en la prevención, tratamiento antineoplásico y supervivencia de pacientes con cáncer de mama
}

\author{
a Departamento de Cirugía General y Aparato Digestivo, Hospital de Mérida, Mérida, España \\ b Departamento de Anatomía e Histología Humanas, Universidad de Zaragoza, Zaragoza, España \\ c Departamento de Farmacología y Fisiología, Universidad de Zaragoza, Zaragoza, España
}

Cristina Marco Continente ${ }^{a}$, María José Luesma Bartolomé ${ }^{b}$ y Sonia Santander Ballestín ${ }^{c, *}$

Recibido el 13 de noviembre de 2019; aceptado el 5 de mayo de 2020

\author{
PALABRAS CLAVE \\ Cáncer de mama; \\ Actividad física; \\ Terapia; \\ Microambiente \\ tumoral; \\ Marcadores biológicos
}

\begin{abstract}
Resumen
Introducción: Durante las 2 últimas décadas, numerosos estudios han investigado el impacto de la actividad física en el tratamiento del cáncer. El objetivo de esta revisión versa en obtener recomendaciones basadas en la evidencia científica publicada más recientemente acerca de la influencia de la actividad física en el cáncer de mama, tanto en lo que se refiere a prevención, así como durante el tratamiento antineoplásico y supervivencia.

Resultados: La actividad física es capaz de interaccionar sobre diferentes mecanismos biológicos típicamente alterados en el cáncer de mama, como son: marcadores inflamatorios, hormonas sexuales, eje insulina/IGF-I, hormonas suprarrenales, vitamina D, sistema inmune, estrés oxidativo y reparación del ADN; dando así resultados positivos en cuanto a disminución del riesgo de carcinogénesis, aumento de calidad de vida y mejora de los efectos secundarios derivados del tratamiento, así como disminución de la recurrencia tumoral y aumento de la supervivencia global.

Conclusión: La actividad física aeróbica y de fuerza-resistencia aparecen ampliamente recomendadas y justificadas en la literatura científica para la prevención y mejora multidimensional de las pacientes con cáncer de mama y supervivientes, estableciendo una serie de precauciones/contraindicaciones ante situaciones de eventual riesgo. El conocimiento de la heterogeneidad del cáncer de mama y de los diferentes mecanismos biológicos implicados en su desarrollo y perpetuación permitirán personalizar la indicación y tratamiento farmacológico/físico para cada paciente.
\end{abstract}

(c) 2020 SESPM. Publicado por Elsevier España, S.L.U. Todos los derechos reservados.

\footnotetext{
* Autora para correspondencia.

Correo electrónico: soniasb@unizar.es (S. Santander Ballestín).
} 


\section{KEYWORDS}

Breast cancer;

Physical activity;

Therapy;

Tumoural

microenvironment;

Biological markers
Influence of physical activity on the prevention, antineoplastic treatment and survival of patients with breast cancer

\begin{abstract}
Introduction: In the last few decades, several studies have investigated the impact of physical activity on the treatment of cancer. The aim of this study was to establish recommendations based on the most recent scientific evidence on the effect of physical activity on breast cancer, in terms of prevention, antineoplastic treatment, and survival.

Results: Physical activity affects various biological mechanisms typically altered in breast cancer, such as inflammatory markers, sex hormones, insulin axis/IGF-1, adrenal hormones, vitamin $D$, the immune system, oxidative stress, and DNA repair. These findings indicate a positive impact in terms of reducing the risk of carcinogenesis, adverse treatment effects and tumoural recurrence, enhancing quality of life, and increasing overall survival.

Conclusion: Aerobic physical activity and strength-resistance training are widely recommended and justified in the scientific literature for prevention and multidimensional improvement in patients with breast cancer and breast cancer survivors, allowing a series of precautions/contraindications to be made in situations of eventual risk. Knowledge of the heterogeneity of breast cancer and of the various biological mechanisms involved in its development and perpetuation will allow personalised indications and drug/physical treatment for each patient.

(c) 2020 SESPM. Published by Elsevier España, S.L.U. All rights reserved.
\end{abstract}

\section{Introducción}

El cáncer, actualmente, constituye una de las primeras causas de muerte en todo el mundo. La mayoría de los factores de riesgo asociados para su desarrollo son ambientales y/o dependientes del estilo de vida; siendo tan solo un $5-10 \%$ de los casos los relacionados con una etiología genéticohereditaria ${ }^{1}$.

La detección temprana y avances actuales en los tratamientos oncológicos han ayudado a mejorar el pronóstico y supervivencia de los pacientes ${ }^{1}$. No obstante, la mayoría de ellos experimentan efectos secundarios derivados de la enfermedad y de los tratamientos dirigidos a su curación, que pueden perdurar en el tiempo, incluso una vez finalizada la terapia antineoplásica. Debido a ello, durante las 2 últimas décadas, numerosos estudios han investigado el impacto de la actividad física en el tratamiento del cáncer ${ }^{1-3}$.

El cáncer de mama constituye el tumor maligno más frecuente en las mujeres a nivel mundial y supone la segunda causa de mortalidad en países desarrollados. Concretamente en España, se detectaron 26.370 nuevos casos en 2017 según la $S E O M^{2}$. Durante la última década, las campañas de «screening», el diagnóstico temprano y la mejora en los sistemas de tratamiento han supuesto un aumento del número de supervivientes, alcanzando una tasa de supervivencia a los 5 años en Europa del 82\%².

En España, el porcentaje de población que nunca hace ejercicio está aumentando (45\% en 2013) y a pesar de que es el segundo país de la Unión Europea donde la caminata regular es más prevalente, la prevalencia de mujeres que no hacen ninguna actividad vigorosa es considerablemente alta ${ }^{4}$. Concretamente, en el cáncer de mama, se ha estimado que entorno al $13,8 \%$ de los casos podrían evitarse si las mujeres inactivas se volvieran activas ${ }^{4}$. Por tanto, el objetivo principal de este trabajo versa en obtener recomendaciones, basadas en la evidencia científica más recientemente publicada, sobre la influencia de la actividad física en el cáncer de mama, tanto en lo que se refiere a prevención, como durante el tratamiento y supervivencia. De este modo, se plantean una serie de cuestiones en la revisión:

- ¿Cómo el estilo de vida influye en el riesgo de padecer cáncer de mama?, ¿La actividad física podría ayudar a prevenir su desarrollo?

- ¿Qué impacto tiene la actividad física en los tratamientos antineoplásicos del cáncer de mama?

- ¿Cuáles son los aspectos moleculares que pueden verse modificados favorablemente por la práctica de actividad física?

- ¿Qué diferencias se encuentran entre las mujeres con cáncer de mama que practican actividad física de las que no? (respuesta al tratamiento, efectos secundarios derivados del tratamiento, calidad de vida, recurrencia, supervivencia)

- ¿La actividad física tiene el mismo beneficio en todos los subtipos de cáncer de mama?

- ¿Qué tipos de actividad física están mayormente recomendados? y ¿En qué situaciones debemos evitarla o contraindicarla?

En este contexto, y con vista a mejorar no solo la supervivencia, sino la calidad de vida de las pacientes, se empieza a investigar sobre el impacto de la actividad física en el cáncer de mama. De este modo, en primer lugar, trataremos de analizar a nivel global cómo el organismo responde ante la actividad física, así como los cambios que se producen en él 
y en el individuo con cáncer, para posteriormente analizar qué es lo que ocurre con respecto al cáncer de mama ${ }^{4-6}$.

\section{Regulación sistémica dependiente de la actividad física}

La integridad y composición del microambiente tumoral (MT) es altamente plástica, experimentando una remodelación constante en respuesta a señales instructivas derivadas de alteraciones en la disponibilidad y naturaleza de los factores sistémicos. La exposición a la actividad física regular ha demostrado reducir marcadamente el riesgo del desarrollo de cáncer; sin embargo, los mecanismos moleculares que sustentan los aparentes efectos antitumorales son poco conocidos $^{1,7}$.

\section{Respuesta en el individuo sano}

En el organismo de un individuo sano, ante la exposición de actividad física aguda, el sistema nervioso central genera una respuesta que modula la coordinación de los sistemas respiratorio y cardiovascular, entre otros, para mantener la perfusión del mismo, y así, incrementar la entrega de oxígeno y nutrientes al músculo esquelético metabólicamente activo. A su vez, se activan vías aferentes tipo ıl y tipo ıv procedentes del músculo esquelético, así como barorreceptores y quimiorreceptores en respuesta a cambios en la presión arterial media, $\mathrm{pO} 2, \mathrm{pCO} 2, \mathrm{pH}$ y temperatura; regulando en su conjunto la respuesta del organismo ${ }^{7-10}$.

Durante la actividad física se producen además reducciones en los niveles de glucemia. Este hecho, promueve la liberación de adrenalina y cortisol por la glándula suprarrenal y de glucagón por el páncreas, que en conjunto, retrasan la hipoglucemia, manteniendo, de este modo, el metabolismo energético de los músculos $7,10,11$.

Por otro lado, la actividad física induce adaptaciones en múltiples procesos celulares en el músculo esquelético. Esto lo podemos observar a diferentes niveles:

\section{Metabolismo}

El agotamiento de los niveles de ATP y $\mathrm{NADH}$ eleva las proporciones de AMP:ATP y NAD+:NADH, activando una serie de sensores metabólicos, incluida sirtuína-1 deacetilasa dependiente de NAD, proteína quinasa activada por AMP, quinasas de la vía MAPK/ERK, p38 proteína cinasa activada por mitógenos y JUN N-terminal quinasa. Estos sensores metabólicos activan la proteína $1 \alpha$ coactivadora del receptor activado por el proliferador de peroxisomas del receptor- $\gamma$ activado por el proliferador de peroxisomas, que regula la expresión de proteínas mitocondriales codificadas en los genomas nuclear y mitocondrial a través de la interacción con múltiples factores de transcripción, como peroxisome proliferator-activated receptor- $\gamma$, estrogen-related receptor- $\alpha$, estrogen-related receptor- $\gamma$, nuclear respiratory factor 1 , nuclear respiratory factor $2 \mathrm{y}$ factor A de transcripción mitocondrial. Acumulativamente, resulta en una biogénesis mitocondrial mejorada, y una reprogramación metabólica, para de este modo, facilitar el aumento de la fosforilación oxidativa en el músculo esquelético (fig. 1) ) $^{7,11}$.

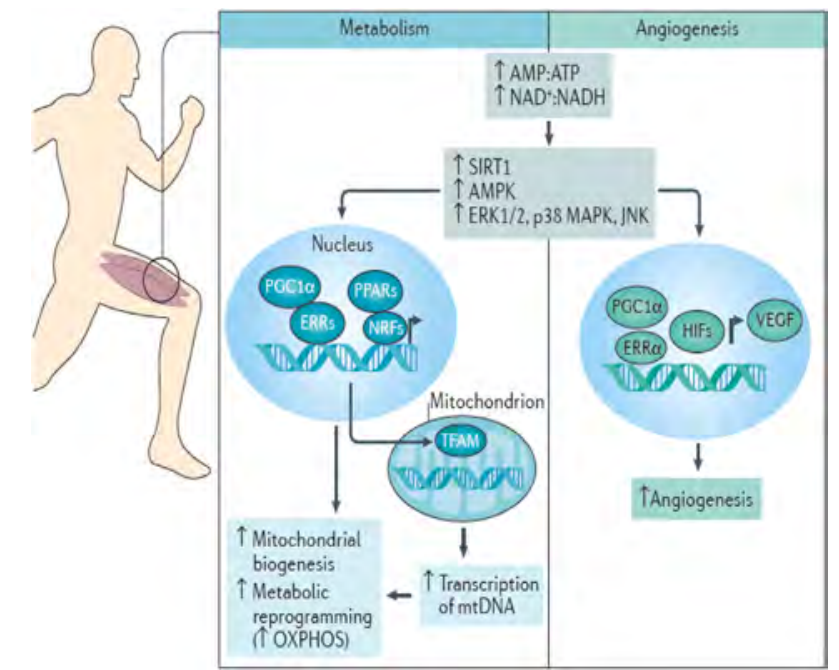

Figura 1 Respuesta metabólica y de angiogénesis en el músculo esquelético ante la actividad física. Fuente: Koelwyn et al. ${ }^{7}$.

\section{Angiogénesis}

La activación inducida por la actividad física de proteína $1 \alpha$ coactivadora del receptor activado por el proliferador de peroxisomas (que regula la expresión de factor de crecimiento endotelial vascular a través de la coactivación de estrogen-related receptor- $\alpha$ ) y los factores inducibles por la hipoxia aumentan a su vez la angiogénesis y la capilarización ${ }^{7,11}$.

\section{Respuesta inmune}

Los episodios de actividad física moderados a vigorosos pueden inducir daño estructural a las fibras musculares. Esto desencadena una respuesta inmune inflamatoria intramuscular, que se caracteriza por un aumento de neutrófilos, monocitos, macrófagos y acumulación de células T CD8+, así como mayores niveles de CC-quimioquina ligando 2, factor de necrosis tumoral (TNF) e interleuquina (IL)-1 $\beta$. Estos inducen la activación de los macrófagos hacia un fenotipo proinflamatorio (M1) y mejoran el reclutamiento de células mieloides. La resolución inflamatoria, después del daño muscular, está coordinada por factores antiinflamatorios tales como IL-10, derivada de células T (Treg) y reguladoras de macrófagos, así como factor de crecimiento transformante $\beta$ y factor de crecimiento insulínico tipo । (IGF-I). El IGF-I producido por los macrófagos también actúa de manera autocrina para activar los macrófagos hacia un fenotipo antiinflamatorio (M2). Estos procesos, finalmente, producen un retorno hacia la normalidad ${ }^{7,11}$.

\section{Respuesta en el microambiente tumoral}

La exposición prolongada a la inactividad física se asocia con concentraciones elevadas de numerosos factores de crecimiento y hormonas, generando un medio protumorgénico. Por el contrario, la exposición a episodios agudos de actividad física estimula la señalización entre órganos mediante la secreción de hormonas, citoquinas y factores de crecimiento, que posteriormente, actúan en múltiples circuitos de control homeostático altamente integrados a nivel 
Tabla 1 Efectos secundarios derivados de los tratamientos antineoplásicos en el cáncer de mama

\begin{tabular}{lll}
\hline Físicos & Funcionales & Psicosociales \\
\hline Fatiga, dolor, náuseas, vómitos, & Disminución de la capacidad & Distrés, ansiedad, depresión, estrés, \\
trastornos del sueño, caquexia, & cardiorrespiratoria, ataxia, pérdida & disminución de la autoestima, \\
cambios de peso, y alteración de la & de tono y atrofia muscular, & pérdida del autocontrol, sensación de \\
imagen corporal asociada a la pérdida & alteraciones en la densidad mineral & aislamiento \\
de pelo, mastectomía y linfoedema & $\begin{array}{l}\text { ósea, neuropatía periférica, } \\
\text { infertilidad, menopausia precoz, } \\
\text { cambios gastrointestinales, daño en } \\
\end{array}$ & \\
& la función inmunológica & \\
\hline
\end{tabular}

Fuente: Ramírez et al. ${ }^{1}$ y Augustin et al. ${ }^{5}$.

celular. Con el tiempo, la perturbación crónica inducida por la actividad física promueve la adaptación fisiológica estimulando la reprogramación en el medio sistémico y alterando potencialmente la disponibilidad y composición en el $\mathrm{MT}^{7}$.

De igual modo, las alteraciones inducidas por la actividad física en el medio sistémico influyen en los mecanismos reguladores clave del MT, como son: angiogénesis, regulación inmune y metabolismo, teniendo así un efecto anti-tumorgénico acumulativo ${ }^{7}$.

\section{Influencia de la actividad física en el cáncer de mama}

\section{Prevención primaria}

Existen múltiples factores de riesgo que se han asociado con el desarrollo de cáncer de mama, muchos de ellos son endógenos y por ello no modificables (sexo, raza, edad, genética...) y otros, sin embargo, son exógenos, y por ello modificables. Es, por tanto, en este punto donde podemos actuar para reducir el riesgo de consecución de la carcinogénesis ${ }^{1,12-16}$.

Estudios recientes han demostrado que uno de los principales factores de riesgo exógenos en el cáncer de mama, tanto en mujeres premenopáusicas como posmenopáusicas (especialmente en este subgrupo), son el sobrepesoobesidad $^{4,11-18}$. El exceso de tejido adiposo genera un aumento del riesgo de cáncer de mama a través de varias vías: incremento de los niveles de hormonas sexuales a través del aumento de la actividad aromatasa y $17-\beta$ hidroxiesteroide deshidrogenasa, reducción de la absorción de glucosa y por tanto generación de un estado de hiperinsulinemia, y en consecuencia una reducción de los niveles de hormona transportadora de hormonas sexuales (SHBG), mayor liberación de IL-6, TNF- $\alpha$, leptina y disminución de adiponectina ${ }^{11,12,15-18}$.

La actividad física, en este contexto, ayudaría a prevenir el desarrollo del cáncer de mama. Así, tal y como se ha evidenciado, Picon-Ruiz et al. ${ }^{12}$ establecen que la actividad física, en sí misma e incluso asociada a la pérdida de peso, disminuye el microambiente inflamatorio, mejora la inmunidad antitumoral, disminuye los niveles de estrógenos y se asocia con un menor riesgo de cáncer de mama. De igual modo, Lope et al. ${ }^{4}$ estiman que la inactividad física está detrás del $10 \%$ de la carga de cáncer de mama en todo el mundo; estableciendo que la actividad física de intensidad moderada parece ser suficiente para observar beneficios en la reducción de riesgo en mujeres premenopáusicas, mientras que las mujeres posmenopáusicas podrían necesitar realizar una actividad física más intensa para obtener el mismo resultado. Asimismo, McTiernan et al. ${ }^{19}$, Lynch et al. ${ }^{20}$ y Leitzmann et al. ${ }^{21}$ respaldan el papel protector de la actividad física, aunque encuentran mayores asociaciones en mujeres de un peso inferior. No obstante, establecen que las mujeres con sobrepeso moderado también se benefician del mismo, especialmente tras la menopausia, tal y como establecen Irwin et al. ${ }^{18}$ y Neilson et al. ${ }^{15}$.

\section{Mejora de la calidad de vida durante el tratamiento antineoplásico}

Las intervenciones terapéuticas derivadas del tratamiento del cáncer de mama pueden causar efectos secundarios, agudos o a largo plazo, que tienden a disminuir la capacidad funcional y a reducir la calidad de vida de las pacientes. Estos efectos secundarios los podemos clasificar en 3 niveles distintos, interrelacionados entre sí (tabla 1) ${ }^{1,5}$.

En este contexto, ha surgido una importante línea de investigación científica en el área de la rehabilitación oncológica, que trata de paliar dichos efectos a través del uso de la actividad física dirigida. Varias revisiones de ensayos clínicos aleatorios y metaanálisis han demostrado una asociación positiva entre la actividad física durante y tras los tratamientos antineoplásicos ${ }^{1}$.

Durante la radioterapia adyuvante, Lipsett et al. ${ }^{3}$ afirman que la actividad física aeróbica y de fuerza-resistencia combinadas resultan prometedoras en lo que se refiere a síntomas como la fatiga. Por otro lado, Steindorf et al. ${ }^{6}$ encuentran un efecto beneficioso en la calidad del sueño y de vida de las pacientes.

Durante la quimioterapia adyuvante Schmidt et al..$^{22}$ afirman que existen beneficios significativos y clínicamente relevantes sobre la fatiga y la calidad de vida si asociamos de forma concomitante actividad física dirigida de fuerzaresistencia progresiva, sugiriendo comenzar de forma precoz para prevenir el círculo vicioso de deterioro de fuerza muscular-baja actividad física-fatiga. Del mismo modo, Van Waart et al. ${ }^{23}$ comparan un programa de actividad física de 2 intensidades diferentes en combinación con quimioterapia, estableciendo que el programa de mayor intensidad fue más efectivo para minimizar la disminución de la 
capacidad cardiorrespiratoria y fuerza muscular, limitando así la fatiga y la carga de síntomas, y evitando en consecuencia la necesidad de reducir dosis de quimioterapia y facilitando, de este modo, la reincorporación laboral precoz; y por otro lado, el de menor intensidad resultó ser una alternativa viable para aquellas incapacitadas para realizar actividad de mayor intensidad.

El Colegio Americano de Medicina Deportiva ${ }^{24}$ establece la seguridad del ejercicio físico tanto aeróbico como de fuerza-resistencia y flexibilidad durante el tratamiento con quimioterapia y radioterapia en el cáncer de mama, encontrando mejoras significativas en la capacidad aeróbica y de fuerza muscular de las pacientes con una evidencia de Categoría A, así como mejoras en el tamaño y composición corporal, calidad de vida y emocional, y fatiga relativa al cáncer con una evidencia de Categoría B. Asimismo, añade que existe evidencia de que el ejercicio físico puede mejorar la función física, la densidad mineral ósea, el rango de movimiento del hombro, el sueño, los niveles de hemoglobina, así como mitigar otros síntomas y efectos adversos asociados con la quimioterapia o radioterapia, incluida la reducción de la duración de la trombocitopenia, las visitas al médico o las hospitalizaciones para tratamiento de complicaciones o síntomas incapacitantes como la diarrea y el dolor con una evidencia Categoría C. Por otro lado, no encuentra evidencia de un aumento en la aparición de linfoedema en la extremidad ipsolateral de las pacientes tratadas con quimioterapia.

Schmitz et al. ${ }^{25}$ y Campbell et al. ${ }^{26}$ en 2 publicaciones recientes actualizan los niveles de evidencia sugeridos por el Colegio Americano de Medicina Deportiva sosteniendo que la actividad física reporta beneficios en los resultados de salud relacionados con el cáncer con un nivel evidencia fuerte con respecto a la reducción de la ansiedad y síntomas depresivos, así como en la disminución de la fatiga relativa al cáncer. Del mismo modo, refieren una mejora significativa en la calidad de vida de las pacientes, así como una mejora la actividad física percibida, sin aumentar el riesgo de linfoedema en la extremidad ipsolateral. Por otro lado, aportan un nivel de evidencia moderado con respecto a la mejora en la calidad de sueño y la densidad mineral ósea. Sin embargo, establecen que existe una insuficiente evidencia para beneficios a nivel de cardiotoxicidad, neuropatía periférica inducida por quimioterapia, función cognitiva, náuseas, dolor, función sexual, así como tolerancia al tratamiento y recaídas.

\section{Impacto de la actividad física en la supervivencia al cáncer de mama}

Para las supervivientes al cáncer de mama, la actividad física también está ampliamente recomendada, y se ha vinculado no solo con mejorías en la calidad de vida y de síntomas asociados tras los tratamientos antineoplásicos, sino también con una disminución en la recurrencia y mortalidad:

Galiano-Castilloo et al. ${ }^{27}$ proponen un programa de tele-rehabilitación vía online (e-CUIDATE) en pacientes supervivientes de cáncer de mama, realizando un seguimiento de 81 voluntarias, y concluyendo que la aplicación de dicho programa ayuda a mejorar y mantener la calidad de vida, el dolor, la fuerza muscular y la fatiga relativa al cáncer. De igual modo, Derry et al. ${ }^{28}$ concluyen en su ensayo controlado aleatorizado que aquellas supervivientes que practicaron yoga tuvieron menor fatiga e inflamación, y un mejor estado emocional. En este contexto, Kim et al. ${ }^{29}$ en su revisión bibliográfica establecen que la actividad física aeróbica y de fuerza-resistencia combinadas parece ser la intervención más efectiva, no solo mejorando la composición corporal y el estado inflamatorio crónico, sino aumentando la resistencia musculoesquelética y los niveles de biomarcadores asociados con la densidad mineral ósea.

Se ha visto que el ejercicio de fuerza-resistencia proporciona mejora en la potencia y la fuerza muscular, así como en la delgadez y la fatiga que las pacientes referían, mejorando el rendimiento físico en mujeres supervivientes de cáncer de mama ${ }^{30}$.

Por otro lado, Schmidt et al. ${ }^{31}$, en su metaanálisis afirman que la mayoría de los estudios analizados informaron de una disminución del $30-40 \%$ en el riesgo de mortalidad general entre las supervivientes de cáncer de mama que realizaron actividad de intensidad moderada de al menos $1 \mathrm{~h} /$ semana. Mientras que Ramírez et al. ${ }^{1}$, en su revisión bibliográfica, encuentran una disminución en la recurrencia y mortalidad en aquellas que caminan entre 3-5 h/semana y de Boer et al. ${ }^{11}$ en aquellas que realizan actividad física de más de 3 MET-hora a la semana, con una correlación positiva dosis-respuesta. Resultados similares son expuestos en la publicación de Haykowsky et al. ${ }^{32}$.

Queda demostrado por tanto, a través de los estudios anteriores, que la actividad física desempeña un papel importante en el cáncer de mama, pero ¿cuáles son los mecanismos biológicos sobre los que la actividad física ejerce su acción? Veámoslo en el siguiente epígrafe.

\section{Marcadores biológicos implicados en el cáncer de mama: influencia de la actividad física}

Tal y como vemos en la tabla 2, hay varios tipos de biomarcadores implicados en el cáncer de mama que se detallan a continuación ${ }^{1,8-13,17,18,20,28,30-35}$.

\section{Marcadores inflamatorios}

El tejido adiposo produce citoquinas y mediadores inflamatorios, creando un ambiente de inflamación crónica que promueve la invasión y metástasis, así como tasas más altas de recurrencia y muerte por varios tipos de cánceres, incluyendo entre ellos el cáncer de mama. La actividad física, en este sentido, ha demostrado reducir la inflamación crónica por sí sola y/o a través de la reducción del peso corporal $^{12,15-17}$. Veamos cómo influye en cada uno de estos parámetros:

\section{Citoquinas pro-inflamatorias}

Aumento de TNF- $\alpha$, IL-6, leptina, y proteína C reactiva (PCR). Estas citoquinas han sido vinculadas con un mayor riesgo de cáncer a través de sus efectos sobre la apoptosis, la proliferación celular, la angiogénesis, y la metástasis ${ }^{1,11,13,15,16,18,36-38}$.

$T N F-\alpha$. Producido por macrófagos que infiltran el tejido adiposo, y por una variedad de células tumorales. Está 
Tabla 2 Biomarcadores implicados en el cáncer de mama

\begin{tabular}{|c|c|}
\hline \multirow[t]{2}{*}{$\begin{array}{l}\text { Marcadores } \\
\text { inflamatorios }\end{array}$} & $\begin{array}{l}\text { La inflamación crónica es un factor de riesgo para la recurrencia y mortalidad por } \\
\text { cáncer de mama }{ }^{1,12,17,18,20,34,35}\end{array}$ \\
\hline & $\begin{array}{l}\text { - Aumento de citoquinas proinflamatorias: TNF- } \alpha \text {, IL-6, leptina, y PCR } \\
\text { - Disminución de citoquinas antiinflamatorias: adiponectina }\end{array}$ \\
\hline Hormonas sexuales & $\begin{array}{l}\text { La exposición prolongada a concentraciones elevadas de estrógenos exógenos y/o } \\
\text { endógenos se ha relacionado con un aumento en el riesgo de padecer cáncer de } \\
\text { mama, especialmente en aquellos subtipos con } \mathrm{RH}+{ }^{12,13,17,18,20}\end{array}$ \\
\hline \multirow[t]{5}{*}{ Resistencia insulínica } & $\begin{array}{l}\text { El aumento de la resistencia a la insulina puede promover el desarrollo de cáncer de } \\
\text { mama por varias vías: }{ }^{1,12,17}\end{array}$ \\
\hline & - Aumento de la hiperinsulinemia, que a su vez provoca: \\
\hline & $\begin{array}{l}\text { - Aumento de los niveles disponibles de IGF-I, estimulando así la diferenciación, } \\
\text { proliferación celular y supresión de la apoptosis }\end{array}$ \\
\hline & - Aumento de la disponibilidad de estrógenos y andrógenos al inhibir SHBG \\
\hline & - Aumento de la glucosa disponible para células neoplásicas \\
\hline $\begin{array}{l}\text { Hormonas de la } \\
\text { glándula suprarrenal }\end{array}$ & $\begin{array}{l}\text { Resultan especialmente importantes en la respuesta inmune antitumoral, así como } \\
\text { con respecto al metabolismo energético, y efectos fisiológicos generalizados }{ }^{8-10}\end{array}$ \\
\hline Vitamina D & $\begin{array}{l}\text { Retrasa e incluso impide la formación de cáncer a través de su actividad } \\
\text { antiproliferativa, apoptótica, antiangiogénica y de diferenciación celular. Niveles } \\
\text { bajos se han relacionado con un mayor riesgo de cáncer de mama }{ }^{5,32}\end{array}$ \\
\hline Sistema inmune & $\begin{array}{l}\text { Una disminución de las células inmunes incrementa el riesgo de desarrollo de } \\
\text { procesos tumorales, así como una mayor susceptibilidad a infecciones }{ }^{11,28,31}\end{array}$ \\
\hline $\begin{array}{l}\text { Estrés oxidativo y } \\
\text { reparación del ADN }\end{array}$ & $\begin{array}{l}\text { La producción de ROS en unos niveles modestos resultan útiles como moléculas de } \\
\text { señalización celular en varios procesos fisiológicos celulares (proliferación, } \\
\text { apoptosis, diferenciación, migración, invasión y angiogénesis). Niveles altos causan } \\
\text { daño oxidativo severo a los componentes celulares, como lípidos, proteínas y ADN, } \\
\text { provocando mayor riesgo de desarrollo de cáncer, entre ellos de mama }{ }^{30,33}\end{array}$ \\
\hline
\end{tabular}

implicado en la defensa del huésped, la inflamación y la organogénesis. Por otro lado, puede inducir apoptosis y necrosis. Niveles crónicamente elevados parecen promover casi todos los pasos que conducen al cáncer ${ }^{11,15,18}$.

IL-6. Se produce predominantemente en forma circulante por fibroblastos, macrófagos, linfocitos, músculo esquelético y tejido adiposo, por lo que la obesidad está fuertemente asociada con el aumento de IL-6, aunque se estima que solo representa el $10 \%$ del total. Por otro lado, TNF- $\alpha$ estimula su liberación, lo que indica que aumentos moderados en IL-6 puede reflejar la producción crónica de TNF- $\alpha$. IL- 6 tiene una amplia gama de funciones reguladoras que implican inflamación y respuestas inmunitarias ${ }^{11,15,18}$.

Leptina. Es una neurohormona y un miembro de la superfamilia de citoquinas. El tejido adiposo es cuantitativamente la fuente más importante de leptina y el principal determinante de sus niveles. La leptina está implicada en los mecanismos de la saciedad, contrarrestando así la ingesta calórica. No obstante, la obesidad se asocia con niveles más altos de leptina, lo que indica resistencia a su acción ${ }^{11,12,15,16,18,37}$.

$P C R$. Es una proteína de fase aguda derivada de los hepatocitos. Supone el marcador prototípico de la inflamación. Está inducida por TNF- $\alpha$ e IL- 6 , y sus niveles se correlacionan positivamente con el exceso de tejido adiposo ${ }^{38-43}$.

En la tabla 3 se especifican las acciones de las citocinas en el cáncer de mama y cómo la actividad física influye en cada una de ellas.

\section{Citoquinas antiinflamatorias}

Se ven disminuidas a favor del estado inflamatorio. Dentro de ellas, la adiponectina desempeña un papel muy importante. En contraste con lo que ocurre con la leptina, la adiponectina tiene una fuerte correlación inversa con la cantidad de tejido adiposo. Además, niveles elevados de TNF- $\alpha$, IL-6 y leptina, resultan ser unos potentes inhibidores de su expresión y secreción. Un aumento de adiponectina produce la inhibición de angiogénesis,

proliferación y de la producción de TNF- $\alpha$ e IL-6, así como un aumento de la sensibilidad a la insulina ${ }^{12,15,18}$.

Entre las mujeres posmenopáusicas, se ha observado una relación inversa entre los niveles circulantes de adiponectina y el riesgo de padecer cáncer de mama, siendo las mujeres con tumores más agresivos las que presentan niveles de adiponectina más bajos. La actividad física ha mostrado ser un promotor de la producción de adiponectina a través de la reducción del tejido adiposo, TNF- $\alpha$ e IL-6, favoreciendo de este modo una disminución del estado inflamatorio en el cáncer de mama. La actividad física a largo plazo puede reducir la inflamación independientemente de la pérdida de tejido adiposo ${ }^{11,12,15,18,37}$.

\section{Hormonas sexuales}

Las hormonas sexuales son quizás el mecanismo potencial más consistentemente citado en la asociación actividad física-cáncer de mama: 
Tabla 3 Marcadores inflamatorios implicados en el cáncer de mama y la influencia de la actividad física

\begin{tabular}{|c|c|c|}
\hline $\begin{array}{l}\text { Citoquina } \\
\text { proinflamatoria }\end{array}$ & Acciones con respecto al cáncer de mama & Efecto de la actividad física \\
\hline \multirow[t]{2}{*}{ TNF- $\alpha$} & $\begin{array}{l}\text { Estimula la producción de IL-6, PCR y estrógenos } \\
\text { (induce la actividad aromatasa) })^{1,11,13,15} \\
\text { Induce resistencia insulínica }{ }^{1,11,13,15,16,18} \\
\text { Causa daño directo del ADN }{ }^{15,18}\end{array}$ & $\begin{array}{l}\text { Reducción de tejido adiposo que } \\
\text { disminuye los niveles de TNF- } \alpha \text { e } \\
\text { IL- } 6^{12,15,18,35}\end{array}$ \\
\hline & $\begin{array}{l}\text { Inhibe la proliferación de células tumorales, aunque } \\
\text { también actúa como promotor tumoral } \\
\text { Promueve la invasión, angiogénesis y } \\
\text { metástasis }{ }^{11,15,18}\end{array}$ & $\begin{array}{l}\text { De forma crónica disminuye el número } \\
\text { de células mononucleares, agotando así } \\
\text { una fuente de TNF- } \alpha \text { e IL- } 6^{12,15}\end{array}$ \\
\hline IL-6 & $\begin{array}{l}\text { Ejerce efectos inhibitorios sobre TNF- } \alpha^{11,15} \\
\text { Estimula la producción de PCR y estrógenos (induce } \\
\text { la actividad de aromatasa) }{ }^{1,11,13,15} \\
\text { Induce resistencia insulínica }{ }^{1,11,13,15,16,18} \\
\text { Regula las proteínas antiapoptóticas y } \\
\text { angiogénicas }{ }^{11,15,18} \\
\text { Promueve la metástasis }{ }^{11,15,18}\end{array}$ & \\
\hline Leptina & $\begin{array}{l}\text { Induce la actividad aromatasa y estabiliza el } \\
\text { receptor de estrógenos- } \alpha^{11,15} \\
\text { Induce resistencia insulínica }{ }^{1,11,13,15,16,18} \\
\text { Su expresión es a su vez estimulada por altos niveles } \\
\text { de estrógenos e insulina }{ }^{11,15,16,18} \\
\text { Mitógeno, antiapoptótico y angiogénico }{ }^{11,15,18}\end{array}$ & $\begin{array}{l}\text { Reducción del tejido adiposo que } \\
\text { produce disminución de la } \\
\text { leptina }^{12,15,18,34,35}\end{array}$ \\
\hline PCR & $\begin{array}{l}\text { Producción inducida por TNF- } \alpha \text { e IL- } 6^{1,11,13,15} \\
\text { Fuertemente relacionado con el aumento de la } \\
\text { resistencia insulínica, modificándose los niveles de } \\
\text { insulina independientemente de los cambios con } \\
\text { respecto a la obesidad } 6^{11,15,16,18}\end{array}$ & $\begin{array}{l}\text { Reducción del tejido adiposo, TNF- } \alpha \text { e } \\
\text { IL- } 6 \text { en el músculo, y células } \\
\text { mononucleares provocan disminución de } \\
\text { PCR }^{12,15,18}\end{array}$ \\
\hline
\end{tabular}

\section{Estrógenos}

Varios metabolitos pueden influir en el riesgo de cáncer de mama, incluyendo estrona (más frecuente en mujeres posmenopáusicas), sulfato de estrona y estradiol (estrógeno endógeno más activo biológicamente). Los estrógenos son mitógenos en la mama a través de la actividad transcripcional mediada por el receptor de estrógenos, y por la activación de las vías de señalización intracelular ${ }^{11,15}$.

\section{Andrógenos}

La testosterona y la androstenediona pueden aumentar el riesgo de conversión a estradiol y estrona, respectivamente, en el tejido adiposo. Por otro lado, pueden actuar directamente sobre las células mamarias al unirse al receptor de andrógenos, un factor de transcripción dependiente de ligandos expresado en la mayoría de los cánceres de mama. Algunos datos clínicos respaldan un papel protector de los mismos $^{11,15}$.

En este contexto, diferenciamos 2 etapas en el ciclo hormonal de la mujer y cómo la actividad física actúa en cada una de ellas:

\section{Mujeres premenopáusicas}

Es el periodo en el cual la mujer se ve expuesta de forma muy importante al papel de las hormonas sexuales, siendo la fase lútea de cada ciclo menstrual la de mayor auge. Cabe destacar el periodo comprendido entre la menarquia y el nacimiento del primer hijo, ya que es el tiempo durante el cual el tejido mamario experimenta una mayor proliferación celular inducida por el estímulo de los estrógenos ${ }^{4,18}$.

Se ha demostrado que mayores niveles de actividad física acortan la duración de la fase lútea, disminuyendo los niveles de progesterona, y aumentando la cantidad de ciclos anovulatorios, evitando así el efecto perjudicial de una exposición prolongada a hormonas sexuales ${ }^{4,11,18}$.

\section{Mujeres posmenopáusicas}

La principal fuente de hormonas sexuales proviene de la conversión de andrógenos adrenales a estrógenos por la enzima aromatasa, que se encuentra en abundancia en el tejido adiposo $^{11,39,41,43-45}$.

Un aumento en la actividad física ayuda a mantener/reducir el exceso de grasa corporal (especialmente abdominal), disminuyendo la actividad aromatasa y de 17- $\beta$-hidroxiesteroide deshidrogenasa; siendo este precisamente el grupo en el cual se encuentran unos mayores beneficios $^{12,14,15,17}$.

Por otro lado, niveles bajos de actividad física y/o exceso de adiposidad en ambos grupos de edad provocan un estado de hiperinsulinemia, que inhibe de forma directa la SHBG, obteniendo, de este modo, un aumento en la biodisponibilidad de hormonas sexuales, además de un aumento del estado inflamatorio, que mediante TNF- $\alpha$ e IL-6 estimulan aún más la expresión de aromatasa en fibroblastos y adipocitos, regulando positivamente la producción de 
estrógenos tanto por el estroma mamario, como por la masa tumoral ${ }^{1,4,11,13,15,16,18}$

Finalmente, debemos tener en cuenta que los efectos de la obesidad sobre el riesgo de cáncer de mama difieren entre mujeres premenopáusicas y posmenopáusicas según el estado de los receptores de estrógenos (RE):

\section{En mujeres premenopáusicas}

La obesidad se asocia con un menor riesgo de cáncer de mama del tipo RE+ y un mayor riesgo de tumores RE-, triple negativo (TN) e inflamatorios ${ }^{4,12,41}$.

\section{En mujeres posmenopáusicas}

La obesidad se asocia con un riesgo marcadamente más alto de cáncer de mama RE+, particularmente en las que no usan terapia hormonal, e inflamatorio, y con un efecto moderado o nulo sobre el riesgo de cáncer de mama RE-- y TN $\mathrm{TN}^{12,39,40}$.

\section{Resistencia a la insulina}

La resistencia a la insulina promueve el desarrollo/perpetuación del cáncer de mama por varias vías:

- La insulina en sí misma, es una hormona anabólica capaz a su vez de aumentar la síntesis y la actividad de IGF-I. Niveles altos de insulina e IGF-I impulsan el crecimiento del cáncer de mama mediante ${ }^{1,5,11,13,15-18}$ :

- La inhibición de la apoptosis y la estimulación de la proliferación celular.

- La estimulación de la angiogénesis.

- La disminución de SHBG, aumentando así la biodisponibilidad de hormonas sexuales.

- El alto índice glucémico generado provoca:

- Obtención de un ambiente adecuado para el crecimiento de las células cancerosas, ya que son ávidas consumidoras de glucosa, debido a su metabolismo alterado caracterizado por la fosforilación oxidativa insuficiente y la fermentación compensatoria de la glucosa; aumentando en consecuencia el ácido láctico y protones que acidifican el microambiente celular externo alcanzando un $\mathrm{pH}$ de 6.5-6.9. Esto proporciona una supervivencia competidora y una ventaja metastásica para las células cancerosas, e induce de forma concomitante resistencia a los fármacos antineoplásicos de base débil ${ }^{5,11}$.

- Aumento del estrés oxidativo, implicado en el daño del ADN dependiente de especies reactivas de oxígeno (ROS), conocido como un contribuyente a la carcinogénesis, aumentando así el riesgo en mujeres previamente sanas y tasas de recurrencia más altas en aquellas con cáncer de mama ${ }^{5,11,33}$.

- Finalmente, el estado de resistencia insulínica se ve favorecido por otras vías, como anteriormente hemos mencionado, a través de mediadores inflamatorios como el TNF- $\alpha$, IL-6 y leptina ${ }^{1,11,13,15,16,18}$.

En este contexto, la actividad física aguda ayuda a aumentar la sensibilidad a la insulina y la absorción de glucosa principalmente a causa de la actividad de los músculos esqueléticos, y la actividad crónica ayuda a reducir los niveles de glucemia, IGF-I e insulina, así como la resistencia a la misma inducida por los marcadores inflamatorios ${ }^{11,13,15,16,18,37,38}$.

Como hemos podido comprobar, los marcadores inflamatorios, las hormonas sexuales y la resistencia insulínica aparecen ampliamente relacionados en la literatura científica en lo que se refiere al aumento de riesgo y desarrollo del cáncer de mama. En la figura 2 modificada de Neilson et al. ${ }^{15}$ observamos la interrelación de todos estos marcadores.

\section{Hormonas de la glándula suprarrenal}

Las hormonas de la glándula suprarrenal contribuyen al riesgo de cáncer de mama, ya que suponen una fuente secundaria de andrógenos, que en sí mismos estimulan el crecimiento celular, y por otro lado, aumentan los niveles de estrógenos a través de su conversión periférica. Adicionalmente, el cortisol actúa como antagonista de la insulina e incluso inhibe su liberación, incrementando así la resistencia insulínica y el estado de hiperglucemia perjudicial en el cáncer de mama. En contra de ello, el cortisol tiene, además, propiedades antiinflamatorias por sus efectos en las citoquinas proinflamatorias, lo cual ayuda a disminuir la inflamación crónica asociada al cáncer de mama ${ }^{8,15,16,18}$.

En los últimos años han surgido estudios que examinan el impacto de la actividad física en los parámetros endocrinos en pacientes con cáncer y supervivientes. Estos estudios indican cambios beneficiosos en la mediación de respuestas inmunes asociadas con la defensa antitumoral, así como en la disminución del estrés y condiciones comórbidas ${ }^{11,31,34}$. Sin embargo, en el estudio realizado por Schmidt et al. ${ }^{31}$ no se encuentran cambios significativos entre el aumento de catecolaminas y cortisol tras actividad física con cambios en el recuento total de células natural killer (NK). Esto es debido, probablemente, a que el tamaño de la muestra no fue el suficiente, y a que muchas de las pacientes del estudio no realizaron una actividad física de rutina, es decir, que no tuvieron continuidad a largo plazo en la realización de la actividad física, que pudo no haber provocado un impacto en la estimulación $\beta$-adrenérgica de las células NK. Por el contrario, Pedersen et al. ${ }^{42}$ en su ensayo clínico revelaron una regulación positiva inducida por la actividad física en las vías asociadas con la función inmune. En este contexto, establecen la regulación positiva inducida por el aumento de epinefrina. Aquellos modelos animales a los que se les aplicó un programa de actividad física tuvieron niveles más altos de epinefrina, lo que indujo una mayor movilización de células NK a través de la estimulación de los receptores $\beta$-adrenérgicos, resultando en una reducción del $61 \%$ en el volumen tumoral en comparación con aquellos que no realizaron actividad física. La administración de propranolol durante la actividad física atenuó por completo el efecto de la epinefrina en el volumen tumoral y en la infiltración de células NK al bloquear la señalización $\beta$-adrenérgica. Asimismo, la epinefrina indujo una movilización selectiva de células NK sensibles a IL-6 inducida por las células musculares durante la actividad física aguda, disminuyendo la frecuencia de células NK inmaduras y aumentando la de células NK citotóxicas.

Por otro lado, los estudios realizados por Evans et al. 8,9 y Tosti et al. ${ }^{10}$ concluyen que existe un mayor grado de 


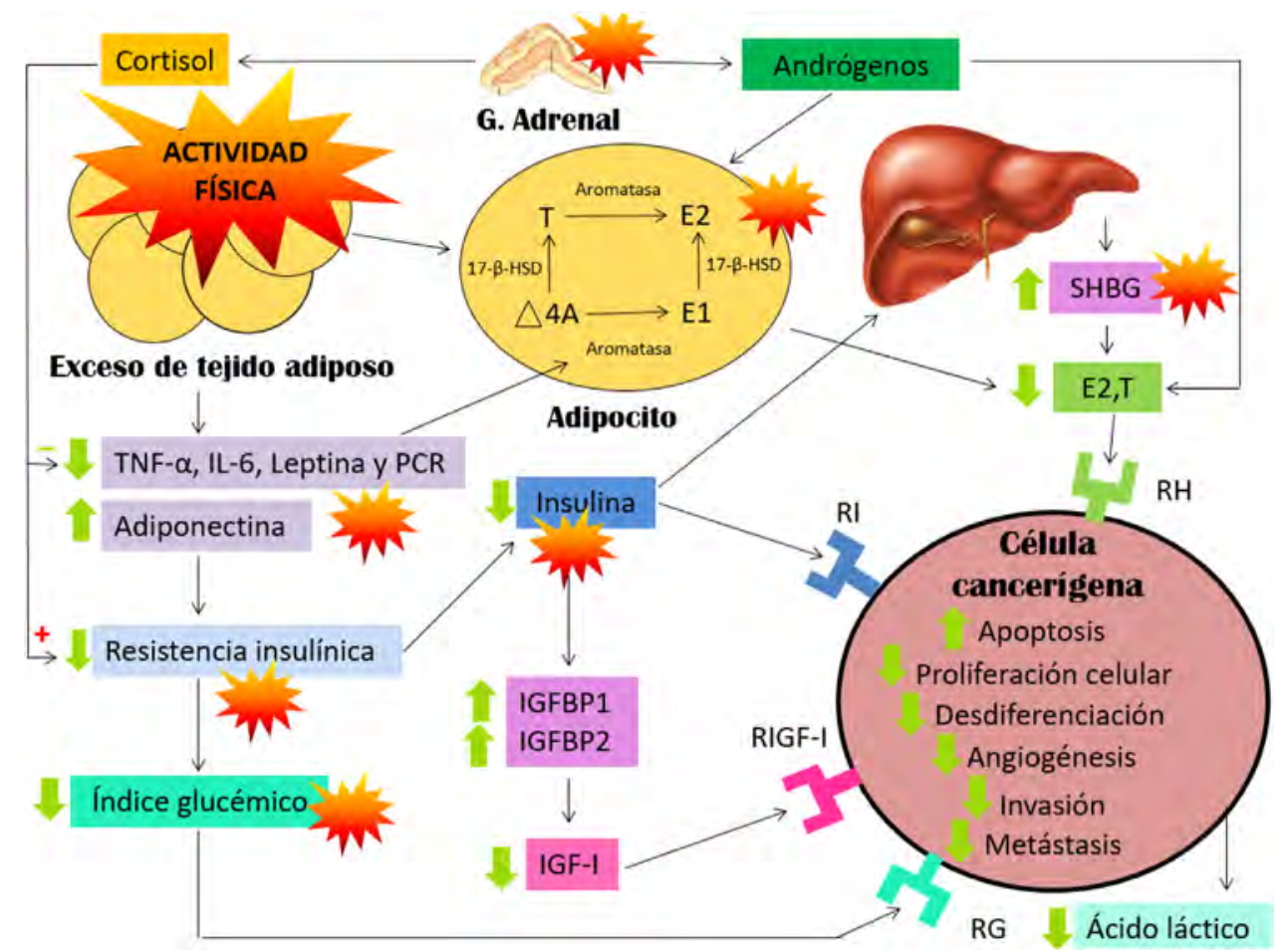

Figura 2 Modelo biológico que relaciona los biomarcadores propuestos con la actividad física a largo plazo y el riesgo de desarrollar cáncer de mama, fundamentalmente a nivel posmenopáusico. Modificado de Neilson et al. ${ }^{15}$.

reactividad crónica al estrés suprarrenal entre las supervivientes a cáncer de mama. Esto queda demostrado a través de las alteraciones significativas encontradas en los patrones de secreción de cortisol, incluyendo alteraciones en el ritmo circadiano del eje hipotálamo-pituitaria-adrenal, así como en la inhibición de retroalimentación del mismo, todo ello consecuencia de la angustia relacionada con el cáncer y los tratamientos antineoplásicos.

\section{Vitamina D}

La vitamina $D$ es una vitamina liposoluble capaz de alterar los genes implicados en el crecimiento celular a través de la regulación positiva de E-cadherina, afectando así a la proliferación, apoptosis, diferenciación, angiogénesis, invasión y metástasis de células neoplásicas ${ }^{5,35}$. Augustin et al. ${ }^{5}$ en su estudio, establecen que niveles séricos de vitamina $D$ más altos (> $30 \mathrm{ng} / \mathrm{ml}$ ) en pacientes con cáncer de mama se han asociado con un $50 \%$ menos de mortalidad en comparación con los niveles más bajos $(<20 \mathrm{ng} / \mathrm{ml})^{6}$.

El estudio transversal de Yang y Toriola ${ }^{35}$ estipula la relación de la actividad física y su influencia con la vitamina D en mujeres supervivientes al cáncer de mama, estableciendo que el ser físicamente activo se asocia con niveles circulantes más altos de 25 hidroxicolecalciferol (25-OHD). El origen de esta relación no está del todo claro. Por un lado, de forma directa, la actividad física puede tener un impacto directo en el metabolismo del 25-OHD, ya que produce mayores tasas de absorción de calcio y niveles de calcitriol en el plasma de personas sanas. Sin embargo, no está demostrado si este mecanismo opera en supervivientes de cáncer, debido a las alteraciones fisiológicas, biológicas y de comportamiento asociadas a la enfermedad y su tratamiento. Por otro lado, de forma indirecta, la actividad física al aire libre puede haber asociado una mayor exposición solar, resultando ser este el principal determinante de los niveles circulantes de 25-OHD.

Además, se observó que aquellas supervivientes de cáncer con obesidad que estaban más activas, tenían niveles circulantes más altos de 25-OHD. Esto hizo postular que el tejido adiposo excesivo induce una dilución volumétrica de vitamina $D$, lo que indica que practicar actividad física es particularmente importante para mantener, o aumentar, los niveles circulantes de 25-OHD en este tipo de población ${ }^{5,32}$.

Finalmente, aunque la relación causal de 25-OHD con la supervivencia del cáncer aún no está clara, una fuerte evidencia respalda los beneficios de la actividad física en la mejora de la supervivencia del cáncer de mama, así como en la calidad de vida de las pacientes. Actualmente, se sugiere que la combinación actividad física-vitamina $D$ puede modificar el MT y conducir a modificaciones epigenéticas. En este contexto, los microARN, pequeñas moléculas de ARN no codificantes, pueden desempeñar un papel fundamental en la modulación de la expresión génica y la progresión del cáncer de mama ${ }^{5,7}$.

\section{Sistema inmune}

La evidencia científica demuestra que aquellas personas con un deterioro del sistema inmune son más susceptibles a desarrollar cáncer e infecciones. La actividad física mantiene y respalda la función inmune celular estableciendo una influencia positiva en términos de desarrollo tumoral ${ }^{11,31,34}$. La intensidad y la duración de la misma son importantes en 
este contexto, ya que exposiciones intensas y prolongadas conducen a una activación mejorada de diferentes partes del sistema inmunitario, al igual que la actividad física regular y moderada, que mejora la función inmune provocando una baja susceptibilidad al cáncer. En contra de ello, el sedentarismo y la actividad física realizada de forma muy intensa pueden tener efectos perjudiciales ${ }^{11,31,34}$.

Numerosos estudios se han publicado acerca del papel que desempeña la actividad física en el sistema inmune de pacientes con cáncer. Estos estudios postulan sobre la relación de la actividad física en el aumento del número y función efectora de monocitos, macrófagos, macrófagos asociados al tumor, células NK, linfocitos y liberación creciente de citoquinas y TNF. En concreto, en el metaanálisis publicado por Schmidt et al. ${ }^{31}$ tratan de analizar dicha relación en el cáncer de mama, estableciendo que se reduce el riesgo de su desarrollo por la mejora

producida en la función inmune. Varios estudios experimentales en ratas son incluidos, demostrando que aquellas que son entrenadas físicamente tienen una mayor población de linfocitos y células dendríticas, así como una función mejorada de los macrófagos ${ }^{43}$.

Un importante papel a destacar es el que desempeñan las células NK, las cuales mediante la práctica de actividad física regular moderada se ha observado una mejora en su número y función, pudiendo así atacar a la mayoría de los tipos de cáncer, así como participar en procesos de supresión tumoral $4,11,12,31,34,43$.

No obstante, debemos tener en cuenta que la función efectora del sistema inmune humano se reduce con la edad avanzada ${ }^{43}$ y con agentes exógenos (especialmente con los tratamientos antineoplásicos), el aumento en la liberación de citoquinas proinflamatorias y antiinflamatorias participan, a su vez, en la regulación del sistema inmune, y que resulta difícil establecer los puntos de corte relevantes de la respuesta inmune inducida por la actividad física ${ }^{31,34}$.

\section{Estrés oxidativo y reparación del ADN}

Cada vez hay más evidencia de que el estrés oxidativo desempeña un papel importante en la progresión de diversos cánceres, entre ellos el cáncer de mama ${ }^{4,11,33,36}$.

El estrés oxidativo consiste en un desequilibrio producido como consecuencia del aumento de ROS, en ausencia de mecanismos de defensa antioxidantes suficientes, produciendo de este modo modificaciones genómicas perjudiciales, que incluyen: inestabilidad cromosómica, daño permanente del ADN, estimulación de oncogenes y mutación de genes supresores de tumores (p53); contribuyendo así a la carcinogénesis. Además, a su vez, las células tumorales producen mayor cantidad de ROS, potenciando aún más este mecanismo ${ }^{11,33,36}$. Por otro lado, el aumento de ROS produce un estímulo de la angiogénesis, a través de la estimulación de IL-8, factor de crecimiento endotelial vascular, y metaloproteinasas de la matriz(colagenasa que ayuda al crecimiento del vaso dentro del MT) e inhibe antiproteasas ${ }^{39}$. Además, aumentan el suministro de sangre mediante vasodilatación y la migración de células tumorales, lo que facilita el riesgo de invasión y metástasis.

El papel que desempeña en este contexto la actividad física se ha atribuido al aumento de la capacidad antioxidante y la disminución de los biomarcadores de estrés oxidativo, en lo

que se ha descrito como: «la paradoja del estrés oxidativo». Este término hace referencia a que cuando se realiza actividad física aguda aumentan contradictoriamente las concentraciones de ROS; sin embargo, con el tiempo, este aumento se produce en el mecanismo de compensación, mediante la regulación positiva de la cantidad y la eficacia de las enzimas antioxidantes ${ }^{11,33,36}$.

Los antioxidantes contrarrestan los aumentos en la producción de ROS, protegen el cuerpo del daño oxidativo al mantener el equilibrio redox, y son fundamentales para preservar una salud y un bienestar óptimos. Los mecanismos de defensa antioxidantes pueden ser enzimáticos (superóxido dismutasa, catalasa, glutatión peroxidasa) y no enzimáticos (vitaminas y/o ciertas moléculas de polifenol introducidas a través de la dieta como glutatión reducido) ${ }^{11,33}$.

En el estudio publicado por Tomasello et al. ${ }^{33}$ tratan de explicar la influencia de la actividad física en el mecanismo del estrés oxidativo en mujeres supervivientes a cáncer de mama; concluyendo que a pesar de la alta producción de ROS, los niveles totales de grupos tiol plasmáticos, que comprenden principalmente glutatión reducido, no se agotaron, pero se mantuvieron dentro del rango normal de referencia, siendo más altos en el grupo de mujeres que hicieron ejercicio de mayor intensidad. Estos datos demuestran los beneficios de actividad física, ya que un alto nivel de glutatión reducido, así como de glutatión peroxidasa y superóxido dismutasa, pueden contrarrestar los efectos del aumento del estrés oxidativo y la lipoperoxidación, como respuesta adaptativa al aumento de ROS circulantes.

En contra de ello, Friedenreich et al. ${ }^{36}$ en su estudio tratan de demostrar el efecto de la actividad física aérobica en los marcadores de estrés oxidativo, así como en las enzimas antioxidantes en mujeres posmenopáusicas, concluyendo resultados no significativos. Sin embargo, en los estudios realizados por De Boer et al. ${ }^{11}$, al igual que Tomasello et al. ${ }^{33}$ demuestran la disminución de estos parámetros asociados a la actividad física, y establecen además que la actividad física aumenta la cantidad de mitocondrias en los músculos, lo que refuerza la resistencia corporal al estrés oxidativo.

Por otro lado, ciertos estudios previos informan sobre la presencia de un mayor daño al ADN basal en pacientes con cáncer de mama sin entrenamiento físico. No obstante, resultados similares se exponen en el grupo control sano. Es bien sabido que la mayoría de los daños son eliminados por las enzimas de reparación del ADN antes de que sean capaces de interferir en la replicación e introducir mutaciones. Por tanto, es probable que la variabilidad interindividual en la capacidad de reparación enzimática sea un factor importante para determinar la susceptibilidad individual al desarrollo de cáncer ${ }^{4,33}$. En este contexto, es posible que la actividad física, induciendo la producción de ROS, pueda estimular un aumento en la capacidad de reparación del ADN a lo largo del tiempo ${ }^{16,36}$.

Finalmente, los datos actuales indican que la medición de diferentes biomarcadores redox sanguíneos y de capacidad de reparación del ADN puede ser un enfoque útil en la definición de una terapia antioxidante individual para apoyar y/o reforzar la eficacia de los tratamientos antineoplásicos; 
y que la actividad física resulta de interés por sus efectos antioxidantes a largo plazo ${ }^{11,33,36}$.

\section{La influencia de la actividad física por subtipo de cáncer de mama}

Debido a la heterogeneidad clínica-molecular del cáncer mama, es posible que diferentes biomarcadores expliquen el riesgo de determinados subtipos de cáncer de mama y que la actividad física interfiera de forma distinta en cada uno de ellos ${ }^{1,4,41}$ :

\section{Receptor de estrógenos y receptor de progesterona}

La información sobre la asociación entre la actividad física y el cáncer de mama según el RE y receptor de progesterona (RP) combinados es escasa, y los resultados son inconsistentes. La reducción del riesgo de cáncer de mama parece ser más pronunciada para los tumores RE-/RP - (reducciones de riesgo entre $20-27 \%$ ) en comparación con los $\mathrm{RE}+/ \mathrm{PR}+$

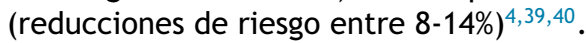

\section{Factor de crecimiento epidérmico humano}

Se encuentra sobreexpresado en aproximadamente el $20 \%$ de las pacientes españolas con cáncer de mama. Actualmente, muy pocos estudios han analizado la asociación entre la actividad física y el cáncer de mama teniendo en cuenta el estado de factor de crecimiento epidérmico humano (HER2), y los resultados de estos estudios también han sido inconsistentes. No obstante, el estudio realizado por Lope et al. ${ }^{4}$ ha permitido demostrar los beneficios de la actividad física en pacientes premenopáusicas, encontrado un efecto protector para todos los fenotipos (RH-/HER2-, RH+/HER2-, $\mathrm{RH}+/$ HER2 + y RH-/HER2+), así como en mujeres posmenopáusicas, especialmente en tumores $\mathrm{HR}+/ \mathrm{HER} 2+$, aunque se requiere una actividad física de mayor intensidad ${ }^{4,45,46}$.

\section{Triple negativo}

Las mujeres premenopáusicas con obesidad tienen un mayor riesgo de tumores TN. No obstante, los estudios son inconsistentes en establecer resultados significativos en la relación actividad física en este subtipo de tumor ${ }^{4,12,41}$.

\section{Guías y recomendaciones para la prescripción de actividad física en el cáncer de mama}

La prescripción de actividad física en pacientes con cáncer de mama debe ser individualizada, teniendo en cuenta los efectos secundarios derivados del cáncer y de los tratamientos antineoplásicos en la capacidad funcional de cada paciente. De este modo, podremos establecer el tipo, intensidad, duración, frecuencia y progresión de la actividad física de forma más segura y efectiva (tabla 4).

\section{Consideraciones generales}

Debemos de tener en cuenta que la actividad física no está exenta de riesgos inherentes. La evidencia ha reportado escasas complicaciones en pacientes oncológicos sometidos a programas de actividad física dirigida, aunque esto es debido a que los criterios de exclusión descartan a aquellos susceptibles de desarrollarlas. Por ello, es necesaria la evaluación previa por un profesional del área de la rehabilitación, con experiencia y formación en el área oncológica, para de esta manera regular y ajustar el programa según el estado físico o emocional de cada paciente. A continuación, se exponen en la tabla 5 aquellas precauciones que debemos tomar en caso de aparición de complicaciones ${ }^{1,2,24}$.

\section{Consideraciones especiales}

Schmitz et al. ${ }^{25}$ establecen que existe suficiente evidencia para respaldar la eficacia de la actividad física para abordar diferentes complicaciones derivadas del cáncer, incluyendo la fatiga, calidad de vida, función física, y el aumento de ansiedad y síntomas depresivos, así como para confirmar la seguridad de la actividad física de fuerza-resistencia entre pacientes con riesgo de desarrollar linfoedema. Veámoslo en apartados de forma más detallada, a continuación:

\section{Fatiga relativa al cáncer}

La fatiga relativa al cáncer es un síntoma inespecífico, generador de distrés, que no cede con el reposo y que permanece durante meses e incluso años tras el tratamiento, suponiendo una merma en la calidad de vida de las pacientes, así como una dificultad en el retorno de la actividad laboral. Campbell et al. ${ }^{26}$ establecen que la fatiga relativa al cáncer persiste en el $25 \%$ de las supervivientes al cáncer por muchos años después de finalizar el tratamiento. En la revisión bibliográfica realizada por Ramírez et al. la 1 afirma que hasta el $80-96 \%$ de las pacientes con cáncer de mama presentan fatiga durante la quimioterapia, y alrededor de un tercio reporta que persiste una vez finalizado el tratamiento. A pesar del incremento del número de estudios en este tema, los mecanismos patofisiológicos concretos que la causan son aún un paradigma. La actividad física y la intervención psicosocial son una forma de tratamiento eficaz para combatirla. Generalmente, un aumento de la dosis de actividad física se corresponde con una disminución de la fatiga, hasta alcanzar un umbral a partir del cual la relación se vuelve directamente proporcional ${ }^{1,5,23,24,30,44}$. Campbell et al. $^{26}$ encuentran que la actividad física de intensidad moderada a vigorosa aporta mayor beneficio en la disminución de la fatiga. Sin embargo, afirman que no hay una evidencia clara al respecto, aunque recomiendan sesiones de ejercicio de más de 30 min y más de 12 semanas de duración. En la tabla 6 se expone una guía de adaptaciones específicas para esta situación.

\section{Linfoedema \\ En las pacientes con cáncer de mama sometidas a cirugía, especialmente con disección y/o radioterapia axi- lar, existe el temor de que la actividad física sea un desencadenante de linfoedema en el brazo ipsolateral. Varios estudios han reportado que la actividad física de}


Tabla 4 Guía y recomendaciones para un programa de actividad física aeróbica

\begin{tabular}{|c|c|}
\hline Tipo & $\begin{array}{l}\text { Actividades que impliquen grandes cadenas musculares: caminar, carrera, ciclismo, elíptica, } \\
\text { natación, tenis... } \\
\text { Observaciones: el tipo de ejercicio queda condicionado a los posibles efectos secundarios } \\
\text { agudos/crónicos relacionados con el tratamiento de la paciente y a las preferencias de la } \\
\text { misma }\end{array}$ \\
\hline Frecuencia & 3-5 sesiones/semana \\
\hline & $\begin{array}{l}\text { Observaciones: para aquellas incapacitadas es preferible un trabajo diario de baja intensidad } \\
\text { y corta duración ( } \pm 3 \text { veces/día y } \pm 10 \mathrm{~min} / \text { sesión) }\end{array}$ \\
\hline Intensidad & Ejercicios de moderada intensidad: \\
\hline
\end{tabular}

50-75\% del VO2 máx o frecuencia cardiaca de reserva (FCreserva)

60-80\% de la frecuencia cardiaca máxima (FCmáx).

Observaciones: es preferible utilizar la FCreserva (1), y a estimaciones la FCmáx (2). El valor de la intensidad queda condicionado al nivel de ejercicio actual de la paciente y a los efectos secundarios de los tratamientos recibidos

Forma de calcularlo:

FCreserva $=$ FCmáx - FCreposo. Posteriormente multiplicar la FCreserva por 0,60 (umbral mínimo) y 0,80 (umbral máximo) y añadir la FCreposo para encontrar el rango de la FC de trabajo.

FCmáx $=220-$ edad en años

Duración 15 a $60 \mathrm{~min}$

Observaciones: es preferible una ejecución continuada, aunque también puede ser espaciada, realizando series más cortas alternadas con períodos de vuelta a la calma

Progresión No aumentaremos la intensidad del ejercicio hasta que la paciente no se adapte al aumento de la duración y secundariamente a la frecuencia del mismo. El ritmo de progresión dependerá de la adaptación cardiovascular

Tipo

Frecuencia Intensidad

Fuerza-resistencia. A cada grupo muscular le asociamos el estiramiento correspondiente para calentar, mantener y mejorar la flexibilidad de los músculos y tendones (unos 10-30 segundos por cada grupo muscular). Se trabajarán principalmente: piernas, pecho, dorso, brazos y abdomen

Observaciones: iniciaremos el trabajo en los músculos más grandes continuando hacia los de menor calibre; e intercalaremos la musculatura de las piernas con la musculatura del tronco 3 sesiones/semana con un día de descanso entre sesiones

- Evaluada según cálculo indirecto de la repetición máxima. El incremento semanal no superará el $10 \%$ del peso inicial calculado. En las fases iniciales la supervisión es imprescindible, incidiendo en:

- Postura: definición y demostración de cómo colocar globalmente el cuerpo de forma higiénica. Implicación analítica del segmento a trabajar

- Biomecánica de la contracción: descripción y demostración de cómo iniciar, progresar y finalizar el arco de movimiento, sin sobrepasar los límites articulares de trabajo y sin causar bloqueos articulares

- Función respiratoria: implicación de la función respiratoria de una forma natural e higiénica sincronizando la inspiración con la contracción concéntrica y la expiración con la recuperación excéntrica

Duración Progresión

2 a 3 series de 15 repeticiones cada una con $1 \mathrm{~min}$ de descanso entre serie y serie Aumentaremos en este orden: $1 .^{\circ}$ repeticiones, $2 .^{\circ}$ series y $3 .^{\circ}$ peso. Una vez conseguido el aumento de repeticiones y series, aumentaremos el peso disminuyendo una serie

Observaciones: siempre se deberá realizar con supervisión e iniciaremos con cargas bajas. No hay límite superior de carga para las supervivientes; sin embargo, se deben controlar los síntomas, incluyendo el linfoedema para evitar su aparición

Fuente: Ramírez et al. ${ }^{1}$; Serdá et al. ${ }^{2}$; Schmitz et al. ${ }^{24}$. 
Tabla 5 Complicaciones asociadas al cáncer de mama y precauciones a tener en cuenta durante los programas de actividad física dirigida

\begin{tabular}{|c|c|c|c|}
\hline Hemoglobina $<8 \mathrm{~g} / \mathrm{dl}$ & $\begin{array}{l}\text { Evitar actividades que } \\
\text { requieran transporte de } 02 \\
\text { elevado }^{2}\end{array}$ & Disnea & $\begin{array}{l}\text { Ejercicio según la } \\
\text { tolerancia, y buscar la } \\
\text { causa de la misma }\end{array}$ \\
\hline Neutrófilos $\leq 0,5 \times 10^{9} \mu / /$ & $\begin{array}{l}\text { Evitar actividades que } \\
\text { pudieran aumentar el riesgo } \\
\text { de infección }{ }^{2}\end{array}$ & Metástasis ósea o dolor & $\begin{array}{l}\text { Evitar ejercicios de alta } \\
\text { intensidad y contacto }\end{array}$ \\
\hline Plaquetas $<50 \times 10^{9} / /$ & $\begin{array}{l}\text { Evitar deportes de alta } \\
\text { intensidad/ impacto }{ }^{1,2}\end{array}$ & Náuseas severas & $\begin{array}{l}\text { Ejercicio según la tolerancia } \\
\text { y buscar la causa de la } \\
\text { misma }^{2}\end{array}$ \\
\hline Fiebre $>8^{\circ} \mathrm{C}$ (axilar) & $\begin{array}{l}\text { Contraindicación parcial y } \\
\text { temporal del ejercicio }{ }^{1,2}\end{array}$ & $\begin{array}{l}\text { Fatiga extrema o } \\
\text { debilitamiento muscular }\end{array}$ & $\begin{array}{l}\text { Ejercicio según la tolerancia } \\
\text { y evaluar la causa }{ }^{1,2}\end{array}$ \\
\hline $\begin{array}{l}\text { Ataxia, mareo, neuropatía } \\
\text { sensorial periférica }\end{array}$ & $\begin{array}{l}\text { Evitar actividades de } \\
\text { equilibrio y coordinación }{ }^{1,2}\end{array}$ & Linfoedema severo & $\begin{array}{l}\text { Evitar cargas en la } \\
\text { extremidad afectada }{ }^{2}\end{array}$ \\
\hline Caquexia severa & $\begin{array}{l}\text { Ejercicio de intensidades } \\
\text { moderadas }^{2}\end{array}$ & Deshidratación & $\begin{array}{l}\text { Consumo adecuado de } \\
\text { fluidos durante la sesión }{ }^{2}\end{array}$ \\
\hline
\end{tabular}

Fuente: Ramírez et al. ${ }^{1}$ y Serdá et al. ${ }^{2}$.

Tabla 6 Adaptaciones especificas ante la existencia de fatiga relativa al cáncer

\begin{tabular}{|c|c|}
\hline Tipo & $\begin{array}{l}\text { Ejercicio aeróbico o programa de condicionamiento muscular de tipo } \\
\text { fuerza-resistencia evitando la natación }{ }^{2}\end{array}$ \\
\hline Frecuencia & $\begin{array}{l}3 \text { sesiones/semana de intensidad moderada intercalando un día de descanso entre } \\
\text { sesiones, o } 5 \text { sesiones/semana de baja intensidad }{ }^{2}\end{array}$ \\
\hline Intensidad & $\begin{array}{l}\text { Se recomienda ejercicio de moderada-baja intensidad, y se desaconseja el trabajo de } \\
\text { alta intensidad debido a la posibilidad de fatiga tardía }{ }^{1,2}\end{array}$ \\
\hline Duración & 15 a 60 min de forma continuada o espaciada con acumulación de periodos $\operatorname{cortos}^{2}$ \\
\hline Progresión & En función de la relación carga/fatiga durante y después de la actividad ${ }^{2}$ \\
\hline
\end{tabular}

Fuente: Ramírez et al. ${ }^{1}$ y Serdá et al. ${ }^{2}$.

fuerza-resistencia resulta segura en estas pacientes, ya que no desarrollaron ni empeoraron el linfoedema de la extremidad, incluso demostrando beneficios significativos con respecto a la fuerza muscular, fatiga y varios dominios de la calidad de vida ${ }^{1,24,25,44}$. Campbell et $\mathrm{al}^{26,47}$ recomiendan un programa de actividad física de fuerza-resistencia, progresivo y centrado en grandes grupos musculares, realizado 2 o 3 veces por semana, y supervisado por un profesional de la materia. Por otro lado, con respecto a la actividad física aeróbica, establecen que, aunque parece ser segura, no existe evidencia suficiente para poder recomendarla en el momento actual.

\section{Aspectos psicológicos y de adherencia a la actividad física}

La práctica de actividad física regular supone también una mejora psicológica. Sin embargo, el paso de una conducta inactiva a activa no se toma de forma instintiva y automática, y resulta incluso más complicado en aquellas que se encuentran en tratamiento o en etapas avanzadas de la enfermedad ${ }^{2}$. Schmitz et al. ${ }^{25}$ establecen que la actividad física solo resulta efectiva en aquellas pacientes que son capaces de seguir el programa de entrenamiento específico, aludiendo a que este cambio de conducta depende de una gran cantidad de factores personales, sociales y ambientales, así como de recursos individuales y comunitarios.
Hay que tener en cuenta que involucrar a las supervivientes de cáncer de mama en la realización de actividad física es un desafío para los profesionales de la salud, como demuestran varios estudios ${ }^{48}$. El estudio realizado por Schmidt et al. ${ }^{41}$ establece que solo un tercio de las pacientes potencialmente elegibles para participar en ensayos clínicos que tratan de demostrar el beneficio de actividad física-cáncer de mama acepta participar, basadas principalmente en la creencia de que el manejo contra el cáncer requiere reposo físico. Otro estudio que pone de manifiesto la dificultad de implicación de las pacientes es el realizado por Dieli-Conwright et al. ${ }^{49}$ observándose la reticencia de algunas pacientes a realizar actividad física durante el tratamiento. Coletta et al. ${ }^{50}$ atribuyen que la mala adherencia a las pautas de actividad física es particularmente más frecuente entre las pacientes con cáncer de mama obesas y aquellas que han recibido una terapia multimodal que incluya cirugía, radioterapia y quimioterapia.

Campbell et al. ${ }^{26}$ establecen que las mejoras en la ansiedad y síntomas depresivos parecen ser mayores en los programas de actividad física con mayor grado de supervisión o supervisados de forma activa, a diferencia de aquellos sin supervisión o realizados en el hogar. Del mismo modo, Schmitz et al. ${ }^{25}$ y Campbell et al. ${ }^{26,47}$ afirman que la derivación de las pacientes a un especialista en actividad física ayuda a evaluar los diferentes factores implicados en una conducta inactiva, y, de este modo, a guiar a las pacientes 
hacia un programa ajustado a sus necesidades y preferencias, que no solo facilita la adopción de la actividad física a través de la fijación de objetivos, establecimiento de tareas graduadas, y el apoyo social, sino que también podría contribuir a reducir la carga de tiempo de los diferentes profesionales médicos implicados en el tratamiento de las pacientes.

La promoción exitosa de la programación de ejercicios a lo largo de las diferentes etapas de tratamiento del cáncer requiere de un cambio de comportamiento no solo a nivel del paciente de forma individual, sino también a nivel de los diferentes profesionales implicados en su tratamiento y seguimiento, así como de la comunidad en general ${ }^{25,26,47}$. Patel et al. ${ }^{51}$ sugieren que para lograr un impacto a gran escala, una amplia participación de expertos en prevención, tratamiento y control del cáncer, colaborando junto con otras partes interesadas, podría ayudar a lograr una visión compartida de un mundo más activo físicamente $\mathrm{y}$, por lo tanto, más saludable.

El establecimiento de programas informativos que traten sobre las estrategias cognitivo-conductuales para la adherencia a la actividad física es un elemento a considerar. Coletta et al. ${ }^{50}$ sugieren enfoques innovadores como aplicaciones móviles para alcanzar y promover sistemáticamente la actividad física en pacientes con factores de riesgo y/o supervivientes de cáncer, y así, poder crear una actitud positiva ante la actividad física, y aumenta el nivel de seguridad de las pacientes. Por otro lado, debemos considerar factores igualmente relacionados como son: el ocio, el hábito, la iniciación, la fuerza de voluntad ${ }^{1,2,29,44}$. Además, Lahart 52 , en su revisión sistemática defienden que las intervenciones de actividad física pueden tener efectos beneficiosos de pequeños a moderados sobre la calidad de vida y sobre la función física, social y emocional percibida, así como sobre la ansiedad, la capacidad cardiorrespiratoria y el rendimiento físico referido por las propias pacientes y medido objetivamente. Sin embargo, advierten que los resultados actualmente deben interpretarse con cautela, debido a que la calidad de evidencia encontrada en la mayoría de los estudios es baja o moderada, a causa de la heterogeneidad de los mismos.

\section{Discusión}

El exceso de tejido adiposo es uno de los principales factores de riesgo en el desarrollo del cáncer de mama. Sin embargo, este riesgo difiere entre mujeres premenopáusicas y posmenopáusicas, siendo este último grupo el más perjudicado, y que por tanto, más se beneficia de la actividad física, tal y como establecen McTlernan et al. ${ }^{19}$, Lynch et al. ${ }^{20}$ y Leitzmann et al. ${ }^{21}$. Sin embargo, también se encuentra beneficio de la actividad

física en mujeres sin sobrepeso, sugiriendo la existencia de otros muchos factores de riesgo implicados.

En este contexto, existe una firme evidencia acerca de los mecanismos que operan en humanos para el desarrollo del cáncer de mama y sobre los cuales la actividad física tiene efecto. Estos se basan principalmente en: marcadores inflamatorios (aumento de citoquinas proinflamatorias como TNF- $\alpha$, IL-6, leptina y PCR, y disminución de citoquinas antiinflamatorias como adiponectina), hormonas sexuales (aumento de hormonas sexuales y disminución de SHBG), resistencia insulínica (eje insulina/IGF-I), hormonas de la glándula suprarrenal (cortisol y catecolaminas), vitamina $D$ (niveles bajos se han relacionado con una mayor mortalidad), sistema inmune (disminución de la inmunidad antitumoral), y estrés oxidativo y reparación del ADN (aumento de ROS y disminución de los sistemas de reparación del ADN) $)^{1,12-18,34-43}$.

En cuanto a la actividad física recomendada, la evidencia reporta que la actividad aeróbica y de fuerza-resistencia en combinación resultan una terapia efectiva y segura tanto en la prevención como en la mejora multidimensional de las pacientes con cáncer de mama y supervivientes. Sin embargo, existe poca evidencia acerca de la frecuencia, duración o intensidad de la actividad física, ya que los estudios son heterogéneos en sus programas de intervención. Es por ello, que deben ser evaluados por un profesional del área de la rehabilitación, con experiencia y formación en el área oncológica, de forma individualizada, estableciendo una serie de contraindicaciones/precauciones durante la misma para evitar aquellos aspectos de eventual riesgo ${ }^{1,8,41}$. Sin embargo, existe el impedimento de la falta de disponibilidad de recursos materiales, así como de personal para llevar a cabo estos programas de actividad física en el ámbito sanitario, reduciendo, de este modo, la capacidad de generar nueva evidencia científica al respecto.

Por otro lado, existen otras limitaciones a la hora de realizar esta revisión bibliográfica que debemos tener en cuenta, como son: el pequeño tamaño muestral de la mayoría de los estudios, la variación en la duración de las intervenciones, la heterogeneidad de las participantes, la falta de evaluación exhaustiva de parámetros que definen la actividad física realizada, la falta de seguimiento y adherencia a los programas de intervención, y la carencia de parámetros reales de actividad en la vida diaria. Por tanto, sería necesario llevar a cabo más estudios aleatorizados y controlados, para poder recomendar la actividad física con un mayor grado de evidencia, tanto en la prevención como durante el tratamiento y periodo de recuperación de las mujeres con cáncer de mama.

Finalmente, una nueva generación de estudios, además de interesarse en abordar todos los defectos hallados anteriormente descritos, debería seguir investigando en el campo del papel de la actividad física por subtipo de cáncer de mama, ya que existe poca información al respecto, y en la mayoría de los casos resulta inconclusa, especialmente en los tumores $\mathrm{TN}^{11}$. De esta forma, en un futuro podremos individualizar de forma más segura y efectiva la actividad física en el cáncer de mama.

\section{Conclusiones}

1. La actividad física es una terapia efectiva, tanto en la prevención del cáncer de mama, así como en la mejora de la calidad de vida, fuerza muscular, disminución de la fatiga y otros síntomas incapacitantes en las mujeres con cáncer de mama y supervivientes, siempre y cuando sea indicada de manera dirigida y supervisada. Los estudios que examinan la relación actividad física-cáncer de mama se encuentran bien determinados y apoyados científicamente para justificar la promoción de la actividad 
física en la mejora multidimensional de las pacientes. Sin embargo, son necesarios más estudios aleatorizados y controlados para poder recomendar la actividad física con mayor grado de evidencia.

2. El conocimiento de la heterogeneidad del cáncer de mama y de los mecanismos biológicos relacionados en la interacción actividad física-cáncer de mama permitirán personalizar la indicación de una forma más efectiva y segura.

3. Resulta fundamental desarrollar políticas públicas en salud, para de esta forma, aumentar la participación de los pacientes oncológicos en programas de actividad física dirigida, a través de la entrega de información adecuada y oportuna, analizando además las necesidades y las barreras en cada población. Asimismo, es igualmente importante educar a otros profesionales sanitarios, para que motiven y estimulen en la participación de estos programas, ya que la adherencia resulta fundamental para mantener los efectos beneficiosos a largo plazo.

\section{Conflicto de intereses}

Los autores declaran no tener ningún conflicto de intereses.

\section{Agradecimientos}

Al Departamento de Farmacología y Fisiología de la Facultad de Medicina, Universidad de Zaragoza

\section{Bibliografía}

1. Ramírez K, Acevedo F, Herrera M, Ibáñez C, Sánchez C. Actividad física y cáncer de mama: un tratamiento dirigido. Rev méd Chile. 2017;145:75-84.

2. Serdá Ferrer, B-C. Cáncer de Mama y ejercicio físico. [tesis doctoral en Internet]. Girona: Universidad de Girona; [citado 4 Ene 2018]. Recuperado a partir de: http://www.sld.cu/galerias/pdf/sitios/rehabilitaciónadulto/c_mama_y_ej_físico-pdf.

3. Lipsett A, Barrett S, Haruna F, Mustian K, O'Donovan A. The impact of exercise during adjuvant radiotherapy for breast cancer on fatigue and quality of life: A systematic review and meta-analysis. Breast. 2018;32:144-55.

4. Lope V, Martín M, Castelló A, Casla S, Ruiz A, Baena-Cañada J, et al. Physical activity and breast cancer risk by pathological subtype. Gynecol Oncol. 2017;144:577-85.

5. Augustin L, Libra M, Crispo A, Grimaldi M, de Laurentiis M, Rinaldo $M$, et al. Low glycemic index diet, exercise and vitamin $D$ to reduce breast cancer recurrence (DEDiCa): Design of a clinical trial. BMC Cancer. 2017;17:1-13.

6. Steindorf K, Wiskemann J, Ulrich C, Schmidt M. Effects of exercise on sleep problems in breast cancer patients receiving radiotherapy: a randomized clinical trial. Breast Cancer Res Treat. 2017;162:489-99.

7. Koelwyn G, Quail D, Zhang X, White R, Jones L. Exercisedependent regulation of the tumour microenvironment. Nat Rev Cancer. 2017; 17:620-32.

8. Evans ES, Hackney A, Pebole M, McMurray R, Muss H, Deal A, et al. Adrenal hormone and metabolic biomarker responses to 30 ?min of intermittent cycling exercise in breast cancer survivors. Int J Sports Med. 2016;37:921-9.
9. Evans ES, Battaglini CL, Groff DG, Hackney AC. Aerobic exercise intensity in breast cancer patients: a preliminary investigation. Integr Cancer Ther. 2009;8:139-47.

10. Tosti KP, Hackney AC, Battaglini CL, Evans ES, Groff D. Exercise in patients with breast cancer and healthy controls: Energy substrate oxidation and blood lactate responses. Integr Cancer Ther. 2011;10:6-15.

11. De Boer M, Wörner E, Verlaan D, van Leeuwen P. The mechanisms and effects of physical activity on breast cancer. Clin Breast Cancer. 2017;17:272-8.

12. Picon-Ruiz M, Morata-Tarifa C, Valle-Goffin J, Friedman E, Slingerland J. Obesity and adverse breast cancer risk and outcome: Mechanistic insights and strategies for intervention. CA Cancer J Clin. 2017;67:378-97.

13. Wu Y, Zhang D, Kang S. Physical activity and risk of breast cancer: A meta-analysis of prospective studies. Breast Cancer Res Treat. 2013;137:869-82.

14. WCRF/AICR, food, nutrition, physical activity, and the prevention of cancer: A global perspective, World Cancer Research Fund/American Institute for Cancer Research; [citado 7 Feb 2018]. Recuperado a partir de: http://www.aicr.org/ assets/docs/pdf/reports/Second_Expert_Report.pdf2007.

15. Neilson H, Friedenreich C, Brockton N, Millican R. Physical activity and postmenopausal breast cancer: Proposed biologic mechanisms and areas for future research. Cancer Epidemiol Biomarkers Prev. 2009;18:11-27.

16. Calle E, Kaaks R. Overweight, obesity and cancer: Epidemiological evidence and proposed mechanisms. Nat Rev Cancer. 2004;4:579-91.

17. Van Gemert W, Monninkhof E, May A, Elias S, van der Palen J, Veldhuis W, et al. Association between changes in fat distribution and biomarkers for breast cancer. Endocr Relat Cancer. 2017;24:297-305.

18. Irwin ML, George SM, Matthews CE. Physical activity and Breast Cancer: Prevention, Survival, and Mechanisms. President's Council on Physical Fitness and Sports Research Digest. 2010; 11:1-9.

19. McTiernan A, Kooperberg C, White E, Wilcox S, Coates R, Adams-Campbell $L$, et al. Recreational physical activity and the risk of breast cancer in postmenopausal women. JAMA. 2003;290:1331-6.

20. Lynch BM, Neilson HK, Friedenreich CM. Physical activity and breast cancer prevention. Recent Results Cancer Res. 2011:13-42.

21. Leitzmann M, Moore S, Peters T, Lacey J, Schatzkin A, Schairer C, et al. Prospective study of physical activity and risk of postmenopausal breast cancer. Breast Cancer Res. 2008;10:579-91.

22. Schmidt M, Wiskemann J, Armbrust P, Schneeweiss A, Ulrich C, Steindorf K. Effects of resistance exercise on fatigue and quality of life in breast cancer patients undergoing adjuvant chemotherapy: A randomized controlled trial. Int J Cancer. 2015;137:471-80.

23. Van Waart H, Stuiver M, van Harten W, Geleijn E, Kieffer J, Buffart L, et al. Effect of low-intensity physical activity and moderate- to high-intensity physical exercise during adjuvant chemotherapy on physical fitness, fatigue, and chemotherapy completion rates: Results of the PACES randomized clinical trial. J Clin Oncol. 2015;33:1918-27.

24. Schmitz KH, Courneya KS, Matthews C, Demark-Wahnefried W, Galvão DA, Pinto BM, et al. American College of Sports Medicine roundtable on exercise guidelines for cancer survivors. Med Sci Sports Exerc. 2010;42:1409-26.

25. Schmitz KH, Campbell AM, Stuiver MM, Pinto BM, Schwartz AL, Morris GS, et al. Exercise is medicine in oncology: Engaging clinicians to help patients move through cancer. CA Cancer J Clin. 2019;69:468.

26. Campbell KL, Winters-Stone KM, Patel AV, Gerber LH, Matthews CE, May AM, et al. An executive summary of reports from an 
international multidisciplinary roundtable on exercise and cancer: Evidence, guidelines, and implementation. Rehab Oncol. 2019;37:144-52.

27. Galiano-Castillo N, Cantarero-Villanueva I, Fernández-Lao C, Ariza-García A, Díaz-Rodríguez L, Del-Moral-Ávila R, et al. Telehealth system: A randomized controlled trial evaluating the impact of an internet-based exercise intervention on quality of life, pain, muscle strength, and fatigue in breast cancer survivors. Cancer. 2016;122:3166-74.

28. Derry H, Jaremka L, Bennett J, Peng J, Andridge R, Shapiro C, et al. Yoga and self-reported cognitive problems in breast cancer survivors: a randomized controlled trial. Psychooncology. 2014;24:958-66.

29. Kim T, Chang J, Kong I. Effects of exercise training on physical fitness and biomarker levels in breast cancer survivors. J Lifestyle Med. 2017;7:55-62.

30. Santagnello SB, Martins FM, de Oliveira Junior GN, de Freitas Rodrigues de Sousa J, Nomelini RS, Murta EFC, et al. Improvements in muscle strength, power, and size and selfreported fatigue as mediators of the effect of resistance exercise on physical performance breast cancer survivor women: A randomized controlled trial. Support Care Cancer. 2020, http://dx.doi.org/10.1007/s00520-020-05429-6.

31. Schmidt T, Hermes A, Weisser B. Physical training influences the immune system of breast cancer patients. Dtsch Z Sportmed. 2017;2017:53-60.

32. Haykowsky M, Scott J, Hudson K, Denduluri N. Lifestyle interventions to improve cardiorespiratory fitness and reduce breast cancer recurrence. Am Soc Clin Oncol Educ Book. 2017;37:57-64.

33. Tomasello B, Malfa G, Strazzanti A, Gangi S, di Giacomo C, Basile $F$, et al. Effects of physical activity on systemic oxidative/DNA status in breast cancer survivors. Oncol Lett. 2016;13:441-8.

34. Evans E, Hackney A, McMurray R, Randell S, Muss H, Deal A, et al. Impact of acute intermittent exercise on natural killer cells in breast cancer survivors. Integr Cancer Ther. 2015;14: 436-45.

35. Yang $L$, Toriola A. Leisure-time physical activity and circulating 25-hydroxyvitamin D levels in cancer survivors: A cross-sectional analysis using data from the US National Health and Nutrition Examination Survey. BMJ Open. 2017;7:e016064.

36. Friedenreich C, Pialoux V, Wang Q, Shaw E, Brenner D, Waltz X, et al. Effects of exercise on markers of oxidative stress: an Ancillary analysis of the Alberta Physical Activity and Breast Cancer Prevention Trial. BMJ Open Sport Exerc Med. 2016;2:e000171.

37. Van Gemert W, May A, Schuit A, Oosterhof B, Peeters P, Monninkhof E. Effect of weight loss with or without exercise on inflammatory markers and adipokines in postmenopausal women: The SHAPE- 2 trial, a randomized controlled trial. Cancer Epidemiol Biomarkers Prev. 2016;25:799-806.

38. Kang D, Lee J, Suh S, Ligibel J, Courneya K, Jeon J. Effects of Exercise on Insulin, IGF Axis, Adipocytokines, and inflammatory markers in breast cancer survivors: A systematic review and meta-analysis. Cancer Epidemiol Biomarkers Prev. 2016;26:355-65.

39. Phipps A, Chlebowski R, Prentice R, McTiernan A, Stefanick M, Wactawski-Wende J, et al. Body size, physical activity, and risk of triple-negative and estrogen receptor-positive breast cancer. Cancer Epidemiol Biomarkers Prev. 2011;20:454-63.

40. Schmidt M, Steindorf K, Mutschelknauss E, Slanger T, Kropp $\mathrm{S}$, Obi N, et al. Physical activity and postmenopausal breast cancer: Effect modification by breast cancer subtypes and effective periods in life. Cancer Epidemiol Biomarkers Prev. 2008; 17:3402-10.

41. Trivers K, Lund M, Porter P, Liff J, Flagg E, Coates R, et al. The epidemiology of triple-negative breast cancer, including race. Cancer Causes Control. 2009;20:1071-82.

42. Pedersen L, Idorn M, Olofsson G, Lauenborg B, Nookaew I, Hansen $\mathrm{R}$, et al. Voluntary running suppresses tumor growth through epinephrine- and IL-6-dependent NK cell mobilization and redistribution. Cell Metab. 2016;23:554-62.

43. Bigley A, Spielmann G, LaVoy E, Simpson R. Can exercise-related improvements in immunity influence cancer prevention and prognosis in the elderly? Maturitas. 2013;76:51-6.

44. Schmidt M, Wiskemann J, Ulrich C, Schneeweiss A, Steindorf K. Self-reported physical activity behavior of breast cancer survivors during and after adjuvant therapy: 12 months follow-up of two randomized exercise intervention trials. Acta Oncologica. 2017;56:618-27.

45. Ma H, Xu X, Ursin G, Simon M, Marchbanks P, Malone K, et al. Reduced risk of breast cancer associated with recreational physical activity varies by HER2 status. Cancer Med. 2015;4:1122-35.

46. Kilbreath S, Refshauge K, Beith J, Ward L, Ung O, Dylke E, et al. Risk factors for lymphoedema in women with breast cancer: A large prospective cohort. Breast. 2016;28:29-36.

47. Campbell KL, Winters-Stone KM, Wiskemann J, May AM, Schwartz AL, Courneya KS, et al. Exercise guidelines for cancer survivors: consensus statement from International Multidisciplinary Roundtable. Med Sci Sports Exerc. 2019;51:2375-90.

48. Pudkasam S, Polman R, Pitcher M, Fisher M, Chinlumprasert N, Stojanovska L, et al. Physical activity and breast cancer survivors: Importance of adherence, motivational interviewing and psychological health. Maturitas. 2018;116:66-72.

49. Dieli-Conwright CM, Courneya KS, Demark-Wahnefried W, Sami $\mathrm{N}$, Lee K, Sweeney FC, et al. Aerobic and resistance exercise improves physical fitness, bone health, and quality of life in overweight and obese breast cancer survivors: A randomized controlled trial 11 Medical and Health Sciences 1117 Public Health and Health Services. Breast Cancer Res. 2018;20:124.

50. Coletta AM, Marquez G, Thomas P, Thoman W, Bevers T, Brewster AM, et al. Clinical factors associated with adherence to aerobic and resistance physical activity guidelines among cancer prevention patients and survivors. PLoS One. 2019;14:e0220814.

51. Patel AV, Friedenreich CM, Moore SC, Hayes SC, Silver JK, Campbell KL, et al. American College of Sports Medicine Roundtable report on physical activity, sedentary behavior, and cancer prevention and control. Med Sci Sports Exerc. 2019;51:2391-402.

52. Lahart IM, Metsios GS, Nevill AM, Carmichael AR. Physical activity for women with breast cancer after adjuvant therapy. Cochrane Database Syst Rev. 2018, http://dx.doi.org/10.1002/14651858.CD011292.pub2. CD011292. 